University of Nebraska - Lincoln

DigitalCommons@University of Nebraska - Lincoln

USDA Wildlife Services - Staff Publications

U.S. Department of Agriculture: Animal and Plant Health Inspection Service

2015

EVALUATION OF ANTHELMINTIC FISHMEAL POLYMER BAITS FOR THE CONTROL OF BAYLISASCARIS PROCYONIS IN FREERANGING RACCOONS (PROCYON LOTOR)

Timothy J. Smyser

Purdue University, Timothy.J.Smyser@aphis.usda.gov

Shylo R. Johnson

USDA/APHIS/WS/National Wildlife Research Center, Fort Collins, Colorado

Melissa D. Stallard

Purdue University

Ashley K. McGrew

Colorado State University

L. Kristen Page

Wheaton College

See next page for additional authors

Follow this and additional works at: https://digitalcommons.unl.edu/icwdm_usdanwrc

Part of the Life Sciences Commons

Smyser, Timothy J.; Johnson, Shylo R.; Stallard, Melissa D.; McGrew, Ashley K.; Page, L. Kristen; Crider, Nikki; Ballweber, Lora R.; Swihart, Robert K.; and VerCauteren, Kurt C., "EVALUATION OF ANTHELMINTIC FISHMEAL POLYMER BAITS FOR THE CONTROL OF BAYLISASCARIS PROCYONIS IN FREE-RANGING RACCOONS (PROCYON LOTOR)" (2015). USDA Wildlife Services - Staff Publications. 1718.

https://digitalcommons.unl.edu/icwdm_usdanwrc/1718

This Article is brought to you for free and open access by the U.S. Department of Agriculture: Animal and Plant Health Inspection Service at DigitalCommons@University of Nebraska - Lincoln. It has been accepted for inclusion in USDA Wildlife Services - Staff Publications by an authorized administrator of DigitalCommons@University of Nebraska - Lincoln. 


\section{Authors}

Timothy J. Smyser, Shylo R. Johnson, Melissa D. Stallard, Ashley K. McGrew, L. Kristen Page, Nikki Crider, Lora R. Ballweber, Robert K. Swihart, and Kurt C. VerCauteren 


\title{
EVALUATION OF ANTHELMINTIC FISHMEAL POLYMER BAITS FOR THE CONTROL OF BAYLISASCARIS PROCYONIS IN FREE-RANGING RACCOONS (PROCYON LOTOR)
}

\author{
Timothy J. Smyser, ${ }^{1,5}$ Shylo R. Johnson, ${ }^{2}$ Melissa D. Stallard, ${ }^{1}$ Ashley K. McGrew, ${ }^{3}$ \\ L. Kristen Page, ${ }^{4}$ Nikki Crider, ${ }^{2}$ Lora R. Ballweber, ${ }^{3}$ Robert K. Swihart, ${ }^{1}$ and \\ Kurt C. VerCauteren ${ }^{2}$ \\ ${ }^{1}$ Department of Forestry and Natural Resources, Purdue University, 715 W State Street, West Lafayette, Indiana 47907, \\ USA \\ ${ }^{2}$ USDA/APHIS/WS/National Wildlife Research Center, 4101 LaPorte Avenue, Fort Collins, Colorado 80521, USA \\ ${ }^{3}$ College of Veterinary Medicine and Biomedical Sciences, Colorado State University, 200 W Lake Street, Fort Collins, \\ Colorado 80523, USA \\ ${ }^{4}$ Biology Department, Wheaton College, 501 College Avenue, Wheaton, Illinois 60187, USA \\ ${ }^{5}$ Corresponding author (email: tjsmyser@purdue.edu)
}

ABSTRACT: Baylisascaris procyonis is a common gastrointestinal parasite of raccoons (Procyon lotor) and is a zoonotic helminth with the potential to cause severe or fatal infection. Raccoons thrive in human-dominated landscapes, and the fecal-oral transmission pathway and lack of effective treatment make B. procyonis a serious threat to public health. The distribution of medicinal baits has emerged as a socially acceptable and cost-effective method for managing disease in free-ranging wildlife. We assessed the suitability of a mass-producible anthelmintic bait for $B$. procyonis mitigation by evaluating the willingness of free-ranging raccoons to consume anthelmintic baits and determining whether bait consumption successfully cleared B. procyonis infections from raccoons. Anthelmintic baits were modified from standard fishmeal polymer baits, the food attractant commonly used in oral rabies vaccine baits, with the introduction of $220 \mathrm{mg}$ of pyrantel pamoate into the fishmeal mixture. We captured 16 naturally infected raccoons, presented one anthelmintic bait, and monitored B. procyonis infection over $90 \mathrm{~d}$ by screening feces for eggs. Treatment cleared B. procyonis infections for nine of 12 raccoons that consumed $>10 \mathrm{~g}$ of the $15 \mathrm{~g}$ bait. We used remote cameras to monitor in situ patterns of bait consumption for anthelmintic baits relative to standard baits. Both anthelmintic and standard baits were rapidly consumed, with no differences in the rate of consumption between bait types. However, after bait contact, raccoons demonstrated a greater willingness to consume standard baits while ignoring anthelmintic baits more frequently $(P=0.06)$. Initial trials of anthelmintic baits show promise, although refinement in both dose and palatability is needed. At mass production scales, the addition of pyrantel pamoate to fishmeal polymer baits would be inexpensive, potentially making anthelmintic baits a viable management option when coupled with an oral rabies vaccine or used independently for B. procyonis mitigation.

Key words: Anthelmintic, baiting, Baylisascaris procyonis, Procyon lotor, raccoon, zoonosis.

\section{INTRODUCTION}

Baylisascaris procyonis is a helminthic zoonosis that can cause severe or fatal infection (Sorvillo et al. 2002; Gavin et al. 2005). As a common gastrointestinal parasite of raccoons (Procyon lotor), the threat posed by B. procyonis to human health extends throughout the distribution of this widespread generalist omnivore, including the raccoon's natural (Central and North America) and introduced (Europe) range (Gavin et al. 2005; Bauer 2013; Page 2013). Mature female B. procyonis are prolific egg producers, with eggs disseminated into the environment through raccoon feces (Page et al. 1998, 1999; Kazacos 2001). Raccoons preferentially defecate at specific microsites (latrines) typically associated with the base of large trees, horizontal substrates (e.g., roofs or fallen logs), or near denning areas (Page et al. 1998; Bauer 2013). Millions of eggs may accumulate at latrines and on surrounding substrates, which serve as foci for infection of human and paratenic hosts. We use paratenic to describe the role of a broad array of small mammals and birds in the lifecycle of B. procyonis, given that 
B. procyonis likely undergoes development to third-stage larvae while in the egg, like other Ascaridinae (Sprent 1992) and can directly infect the definitive raccoon host through the ingestion of these infective eggs (D. Bowman pers. comm.; Page et al. 1999; Kazacos 2001). Eggs are resilient in the environment and, in appropriate substrates, remain viable for many years (Kazacos 2001). Therefore, latrines may serve as a source of environmental contamination even in the absence of apparent raccoon feces. Following the incidental ingestion of larvated eggs, the eggs hatch and larvae begin aggressive somatic migration with human disease attributable to the invasion of the viscera, eye, or central nervous system (Sorvillo et al. 2002).

Raccoons are synanthropic, readily adapting to human-dominated landscapes. Densities in agricultural, suburban, and urban landscapes often exceed those in natural habitats (Page et al. 2001; Hadidian et al. 2010). The ability of raccoons to thrive in human-dominated landscapes, the fecal-oral transmission pathway, and lack of effective treatment options make B. procyonis a serious public health threat. Since B. procyonis was described as a causative agent of human disease (Huff et al. 1984), at least 30 severe or fatal infections have been reported (Gavin et al. 2005; Haider et al. 2012; Hernandez et al. 2013). Furthermore, the severity of this threat appears to be increasing with the geographic expansion of $B$. procyonis and recent increases in severe infection (Blizzard et al. 2010; Chavez et al. 2012; Hernandez et al. 2013; Pipas et al. 2014).

The distribution of vaccine-laden or medicinal baits is often used to manage some zoonotic diseases among free-ranging wildlife, and such disease-management efforts may be appropriate for B. procyonis mitigation. Oral rabies vaccination (ORV) has been used to eliminate rabies from numerous wildlife, including red fox (Vulpes vulpes) populations in Western and Central Europe and Ontario, Canada (MacInnes et al. 2001; Freuling et al.
2013) and coyote (Canis latrans) populations in south Texas (Sidwa et al. 2005). Most notably, widespread annual distribution of ORV baits is the primary tool in an active management program that seeks to prevent the expansion of the raccoon rabies variant enzootic region beyond the eastern US (Slate et al. 2009). Additionally, medicinal anthelmintic baits have been used in numerous landscape-scale field trials in Europe and Japan to control Echinococcus multilocularis, a common zoonotic helminth of red foxes and the causative agent of human alveolar echinococcosis (Tsukada et al. 2002; Hegglin et al. 2003; Hegglin and Deplazes 2013). Using baits to treat free-ranging wildlife for localized control of a parasitic agent poses unique challenges relative to protecting susceptible individuals with vaccine-laden baits. Unlike vaccines, consumption of an anthelmintic bait conveys no protective immunity because hosts remain susceptible to reinfection; furthermore, in the complex life cycle of a parasite such as E. multilocularis, environments contaminated with infective eggs or metacestode stages within intermediate host populations serve as disease reservoirs that are unaffected by anthelmintic baiting (Hegglin and Deplazes 2013). Therefore, repeated baiting is needed to obtain management objectives.

Building on established methods of using anthelmintic baits to manage parasitic zoonoses and the development of bait delivery systems attractive to raccoons, preliminary experiments have extended the application of anthelmintic baits to manage B. procyonis infection in freeranging raccoons (LoGiudice 1995; Page et al. 2011; Smyser et al. 2013). Field trials employed a fishmeal polymer attractant (Bait-Tek, Orange, Texas, USA) that was developed for delivery of an oral rabies vaccine (RABORAL V-RG ${ }^{\circledR}$ fishmeal block; Merial, Duluth, Georgia, USA) and was readily accepted by raccoons relative to other bait types (Hanlon et al. 1989). Baits were modified from ORV 
baits in that the hollow chamber of the attractant was filled with a dose $(90 \mathrm{mg}$ [base]) of the general anthelmintic pyrantel pamoate mixed with marshmallow cream and sealed within the chamber with melted paraffin wax (Page et al. 2011; Smyser et al. 2013). The monthly distribution of anthelmintic baits successfully reduced levels of environmental contamination as measured by the prevalence of B. procyonis eggs in raccoon feces found at latrines (Page et al. 2011; Smyser et al. 2013). Furthermore, Page et al. (2011) observed reduced $B$. procyonis infection of paratenic hosts (white-footed mice [Peromyscus leucopus]) within treated areas, suggesting that repeated bait distribution disrupted pathogen transmission dynamics. The multiple components of these baits (fishmeal attractant, anthelmintic, marshmallow cream, paraffin wax) make them expensive and labor intensive to assemble, limiting their suitability for broad-scale management applications. By integrating an anthelmintic directly into the fishmeal attractant, a bait could be produced that is cost effective and suitable for mass production. However, questions remain as to whether the bait manufacturing process would compromise the efficacy of the drug (Johnston et al. 2005) and if the introduction of a drug into the fishmeal attractant would reduce the willingness of raccoons to consume the bait (Hanlon et al. 1989). We evaluated the suitability of an anthelmintic fishmeal polymer bait (anthelmintic bait) for B. procyonis mitigation by examining 1) whether the consumption of an anthelmintic bait would successfully clear B. procyonis infection in naturally infected raccoons and 2) the willingness of free-ranging raccoons to consume anthelmintic baits relative to standard fishmeal polymer baits.

\section{MATERIALS AND METHODS}

\section{Anthelmintic fishmeal polymer baits}

Anthelmintic baits were modified from standard fishmeal polymer baits (Bait-Tek) with the introduction of pyrantel pamoate directly into the fishmeal matrix. Pyrantel pamoate was effective for clearing $B$. procyonis infections in naturally infected raccoons when delivered at $20 \mathrm{mg} / \mathrm{kg}$ (Kazacos 1986; Bauer and Gey 1995). Pyrantel pamoate has a wide margin of therapeutic safety, making it an appropriate drug for introduction into the environment. Anthelmintic baits were produced for this experiment by Bait-Tek using standard production protocols with a modified bait composition in which pyrantel pamoate (Sigma-Aldrich Corporation, St. Louis, Missouri, USA; $4.3 \%$ by weight) was added to the standard bait mixture (fishmeal, binder agent, and fish oil). We designed baits to deliver a therapeutic dose for raccoons in the 95th percentile by weight $(11 \mathrm{~kg} ; \mathrm{S}$. D. Gehrt pers. comm.). Accordingly, each $15-\mathrm{g}$ anthelmintic bait delivered $220 \mathrm{mg}$ of pyrantel (base).

\section{Captive trials}

We used live traps (Tomahawk Live Trap, Hazelhurst, Wisconsin, USA) baited with commercial cat food to collect 21 adult raccoons from Larimer County, Colorado, over a 4-wk period starting in June 2013; individuals $<5 \mathrm{~kg}$ or actively lactating were released at the capture location. We anesthetized captured raccoons with ketamine/xylazine $(10 \mathrm{mg} / \mathrm{kg}$ ketamine and $2 \mathrm{mg} / \mathrm{kg}$ xylazine, intramuscularly [Fowler 2009]). Upon induction, animals were weighed and implanted with a passive integrated transponder tag (Avid Identification Systems, Norco, California, USA), and blood samples were collected. We transported raccoons to animal care facilities at the National Wildlife Research Center, Fort Collins, Colorado, where they were placed in individual pens $(3 \times 3 \times 2.5 \mathrm{~m})$ with a den box and enrichment structures.

Following release into pens, we collected the first fecal sample available to assess $B$. procyonis infection at the time of collection. For 16 of the 21 raccoons used in the trial, we presented one anthelmintic bait immediately after the first fecal collection. If fecal collection occurred on the same day as capture, the anthelmintic bait was the only source of food available during the first night in captivity. If the animal did not defecate within $24 \mathrm{~h}$ of collection, we provided a daily food ration (180 g, Mazuri Omnivore, PMI Nutrition International, Brentwood, Missouri, USA) until fecal collection occurred. Once feces were collected from these individuals, one anthelmintic bait was provided with the daily food ration, although the food ration was removed at the end of the day, leaving only the anthelmintic 
bait overnight. We maintained this pattern of food and bait availability for five nights or until the bait was consumed; after five nights any uneaten portion of the bait was removed. In response to the reluctance of some of the first 16 raccoons used in the trial to consume an anthelmintic bait directly, we crumbled and mixed an anthelmintic bait with $155.9 \mathrm{~g}$ of moist cat food for the final five raccoons added to the captive population after these animals had been held in captivity up to $20 \mathrm{~d}$. We removed any remaining cat food after $24 \mathrm{~h}$ and evaluated how much of the cat food/bait mixture had been consumed.

To determine whether bait consumption effectively cleared $B$. procyonis infections, we performed fecal flotation (Foreyt 2001) on samples collected before treatment (described earlier) and 7, 14, 28, 60, and $90 \mathrm{~d}$ after presentation of an anthelmintic bait. Samples were individually collected and stored frozen until they were screened for B. procyonis eggs. Because freezing negatively affects the ability of parasite elements to float (Foreyt 1986; Van Wyk and Van Wyk 2002), we also examined the sediment that remained on the bottom of the tube for eggs following centrifugation. Additionally, we visually examined fecal samples collected 1-4 d after anthelmintic bait consumption for passed nematodes. If eggs were present on day 14 after bait consumption, we provided an additional bait mixed in cat food, as described above, within $6 \mathrm{wk}$ of the initial presentation of the anthelmintic bait. If infection persisted through two doses with anthelmintic baits, raccoons were dewormed with liquid pyrantel pamoate $(20 \mathrm{mg} /$ $\mathrm{kg}$ ) mixed in cat food. Activities associated with these captive trials were approved by the USDA National Wildlife Research Center Institutional Animal Care and Use Committee under protocol QA-2111.

\section{Field trials}

To evaluate palatability of anthelmintic baits, we conducted field trials using remote cameras to monitor patterns of bait consumption for anthelmintic baits relative to standard fishmeal polymer baits. Trials were conducted in three disjunct mature hardwood forest patches in Tippecanoe County, Indiana, between 19 September and 7 November 2013. Each forest patch was adjacent to row crop agriculture with exurban development nearby and had water available in ponds or creeks. For each trial, we tethered either an anthelmintic or standard bait to a tree so that animal interactions with the bait could be captured by a remote camera. Specifically, we looped

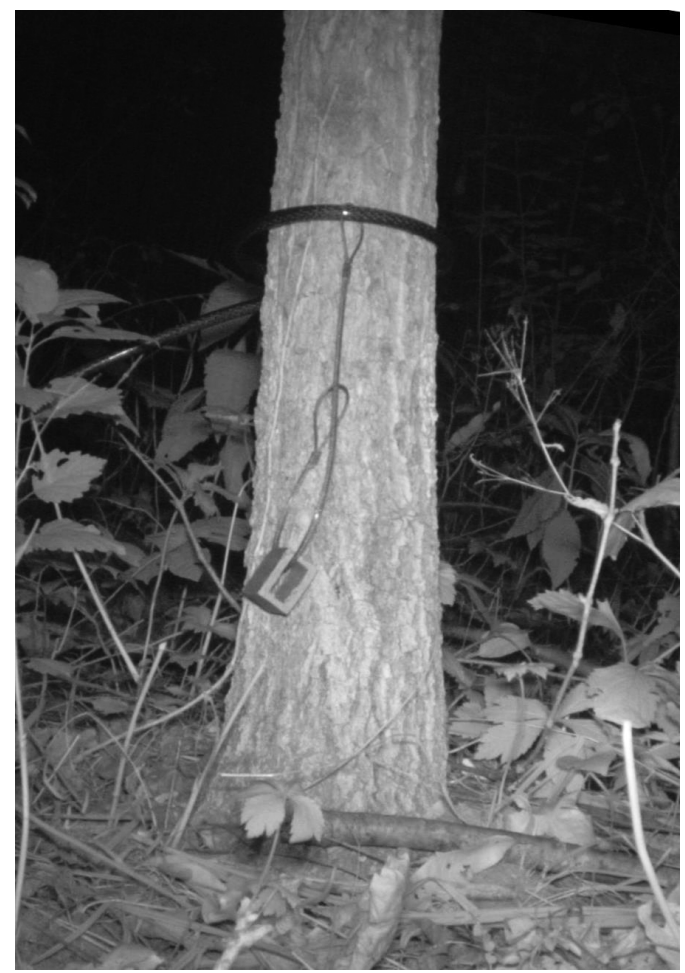

Figure 1. Experimental setup used to monitor via remote camera in situ bait consumption for standard fish meal polymer baits and experimental anthelmintic baits (220 mg pyrantel pamoate [base] added to standard bait mixture of fishmeal, fish oil, and binding agent) in three disjunct forest patches in Tippecanoe County, Indiana, USA, in 2013.

a $1.6-\mathrm{mm}$ wire rope through the empty chamber of the bait and attached the wire rope to the tree so that the bait was $15 \mathrm{~cm}$ above the forest floor (Fig. 1). We then affixed a motion-activated, camera (PC900, RECONYX Inc., Holmen, Wisconsin, USA) to an adjacent tree with the camera programmed to capture images continuously through the duration of the detected motion (approximately two images per second). Additionally, we programmed cameras to capture a time-lapse image every $30 \mathrm{~min}$; this allowed us to identify the time the bait was consumed if the camera failed to detect the bait removal. We established camera stations in a grid with $100-\mathrm{m}$ spacing throughout the forest patches, alternating bait type (anthelmintic versus standard) between adjacent stations. Bait densities of $100 / \mathrm{km}^{2}$ were realistic for management applications, similar to densities in raccoon rabies ORV baiting ( 75 or 150 baits $/ \mathrm{km}^{2}$; Slate et al. 2009). We maintained six to nine cameras at 
a time, moving camera stations through the grid after each trial. Trials began at sunset on day 1 for all cameras deployed simultaneously. We used imagery and associated time stamps to identify the outcome of bait contact (consume or ignore), the species contacting the bait, and the time the interactions occurred. We calculated Kaplan-Meier estimates to evaluate differences between bait types in the time to consumption and conducted a test of equal proportions to evaluated whether the proportion of baits consumed by raccoons as opposed to nontarget species differed by bait type. Characterizing the outcome of raccoon visits to a bait as either consume (1) or ignore (0), we used logistic regression to evaluate the influence of bait type on the probability that a raccoon consumed the bait. All of these analyses were conducted in $\mathrm{R}$ ( $\mathrm{R}$ Development Core Team 2014). All in situ assessments of bait consumption conformed to Purdue University Animal Care and Use Committee policies (Protocol 1211000761).

\section{RESULTS}

\section{Captive trials (Table 1)}

Of the 21 raccoons in the captive trial, 16 had patent infections, actively shedding B. procyonis eggs at the time of capture. Of the 16 raccoons that were presented an anthelmintic bait directly, the willingness to consume a bait varied among individuals, with five consuming the entire bait, four consuming $>10 \mathrm{~g}$ but less than the entire bait, five consuming a small portion of the bait (1.26-3.78 g), and two consuming $<1 \mathrm{~g}$. Of the subsequent five raccoons that were presented a crumbled bait mixed with moist cat food, three consumed the entire mixture, whereas two consumed only a small portion and therefore received a reduced pyrantel dose.

Of the 16 infected raccoons, 10 consumed $>10 \mathrm{~g}$ of an anthelmintic bait (directly $n=7$, mixed with cat food $n=3$ ). Of these 10 individuals, seven were no longer shedding eggs when re-evaluated 7 $\mathrm{d}$ postbait consumption, nor were eggs detected during the 90-d monitoring period. Two of the three raccoons with persistent infections were presented with a second anthelmintic bait. Of these two raccoons, B. procyonis infection was cleared in one, as indicated by lack of eggs in the feces. The second continued to shed eggs after the consumption of a second bait; a third treatment with liquid pyrantel pamoate also failed to eliminate $B$. procyonis. Of the six infected raccoons that consumed only a portion of the first bait, four were no longer shedding eggs when evaluated at $14 \mathrm{~d}$. For the remaining two raccoons, infections were cleared with the complete consumption of a second anthelmintic bait mixed in cat food. Two of the four raccoons that ceased shedding eggs $14 \mathrm{~d}$ after partial bait consumption resumed egg shedding later in the trial (eggs detected at $28 \mathrm{~d}$ for one raccoon and 60 and $90 \mathrm{~d}$ for the second); however, these individuals were not treated a second time within the context of this study.

Of the 16 raccoons collected with patent infections, adult B. procyonis were observed in feces of 13 raccoons shortly after initial bait consumption (8/10 with complete bait consumption; 5/6 with partial bait consumption). Of the five individuals for which infection persisted after the consumption of either a complete $(n=3)$ or partial $(n=2)$ bait, nematodes were observed in the feces of three. No nematodes were detected in the feces of the five raccoons that were not shedding eggs at the time of capture.

\section{Field trials}

We conducted 70 bait trials (36 anthelmintic, 34 standard baits) from which the time to bait consumption could be determined for 60 baits (32 anthelmintic, 28 standard baits; four anthelmintic and two standard baits were still present when cameras were serviced and therefore censored for survival analysis), and the species consuming the bait was identified for 51 trials (27 anthelmintic, 24 standard baits; cameras failed to detect motion associated with bait removal of five anthelmintic and eight standard baits). 


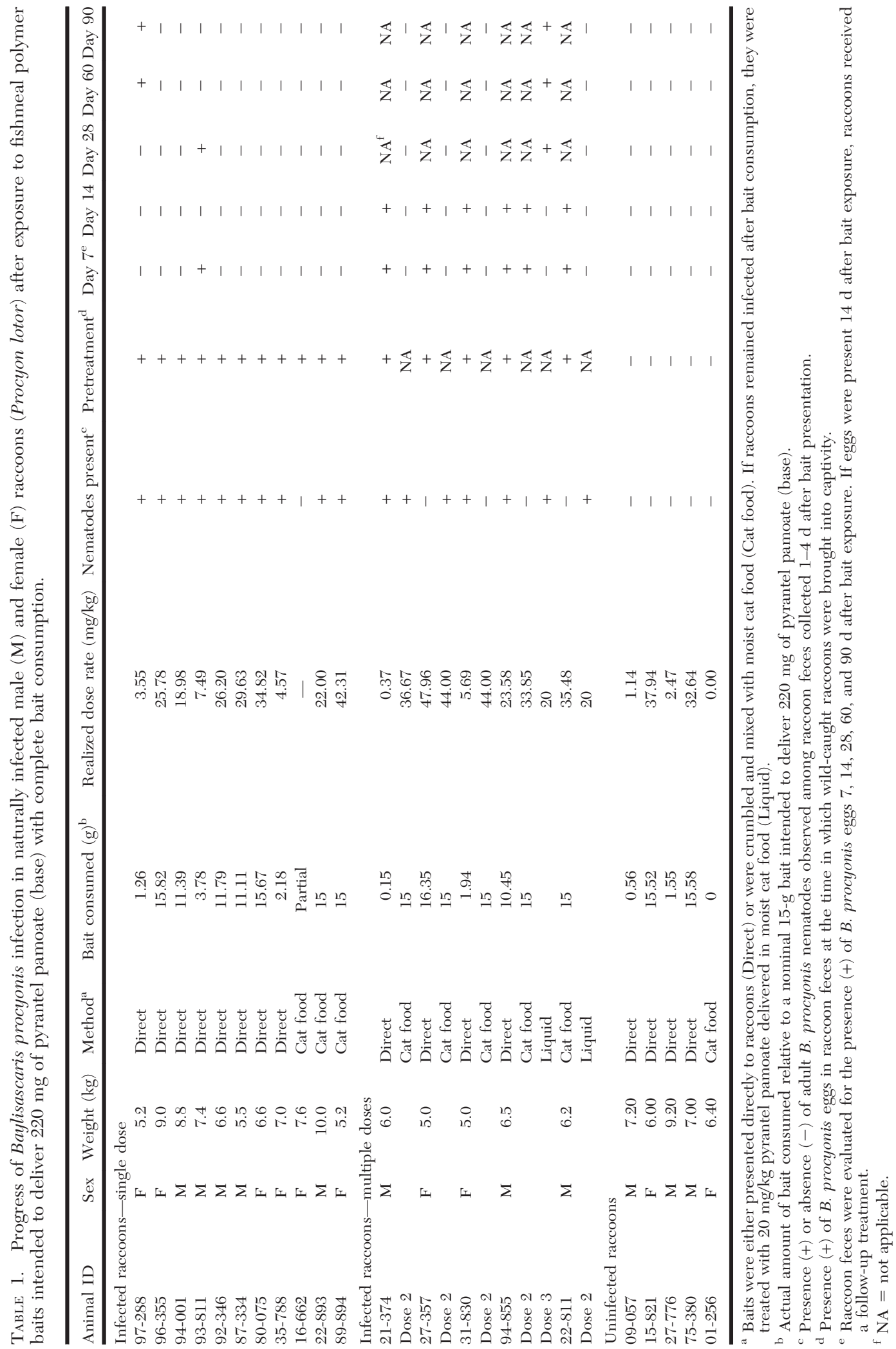




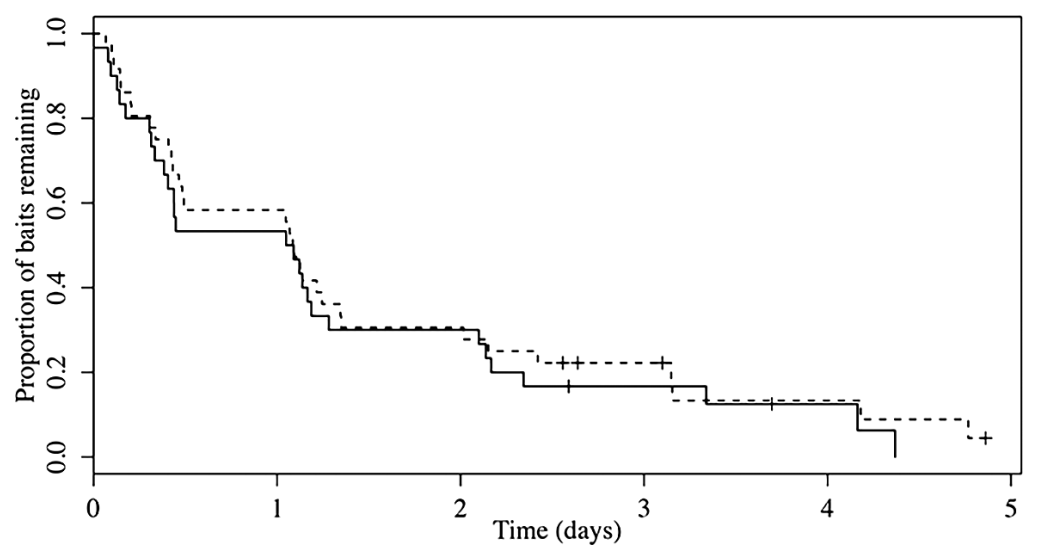

Figure 2. Proportion of standard (solid line) fishmeal polymer baits and experimental anthelmintic (dashed line) baits (220 mg pyrantel pamoate [base] added to standard bait mixture of fishmeal, fish oil, and binding agent) remaining during bait consumption trials conducted in three disjunct forest patches in Tippecanoe County, Indiana, USA, with bait consumption monitored by remote cameras. Baits that remained unconsumed at the conclusion of the trial period were right censored for analysis and are indicated with + .

Both bait types were consumed rapidly in situ (Fig. 2) with 44\% (15/36 anthelmintic; $14 / 30$ standard) consumed in the first night, $70 \%$ by the end of the second night (25/36 anthelmintic; 21/30 standard), and $80 \%$ by the end of the third $(28 / 36$ anthelmintic; 25/30 standard). There was no difference in the rate of bait consumption between the two bait types $\left(\chi^{2}=0.40\right.$, $\mathrm{df}=1, P=0.50)$. Of the trials in which we could identify the species consuming the bait, raccoons consumed 10 of $27(37 \%)$ anthelmintic baits and 12 of $24(50 \%)$ standard baits. Differences in the proportion of baits consumed by raccoons were not statistically significant $\left(\chi^{2}=0.42\right.$, $\mathrm{df}=1, P=0.52)$. Raccoons approached anthelmintic baits on 39 occasions and consumed 10 of these baits, whereas raccoons contacted standard baits on 21 occasions and consumed 12 baits. Bait type was a significant predictor of the outcome of bait contact by raccoons $(P=0.02$, odds ratio $=3.89$ for standard vs. anthelmintic), indicating that, upon encounter, raccoons were more willing to consume standard baits than anthelmintic baits. Virginia opossums (Didelphis virginiana) were the only nontarget species that consumed baits (consuming 17 anthelmintic in 24 encounters and 12 standard in 12 encounters). We observed bait contact by flying squirrels (Glaucomys volans) and white-footed mice on multiple occasions; however, these small-bodied animals were unable to remove baits from tethers.

\section{DISCUSSION}

Anthelmintic fishmeal polymer baits were moderately effective for eliminating $B$. procyonis infections in naturally infected raccoons. Infections were eliminated in nine of 12 raccoons when individuals consumed $>10 \mathrm{~g}$ (of $15 \mathrm{~g}$ ) of a bait, resulting in realized dose rates of 18.9$48.0 \mathrm{mg} / \mathrm{kg}$. Of those individuals with persistent infections, the presence of adult B. procyonis in feces suggests that parasite numbers were reduced, although not eliminated, with bait consumption. Bauer and Gey (1995) found that one dose of pyrantel delivered in food at $20 \mathrm{mg} / \mathrm{kg}$ cleared $100 \%$ of B. procyonis infection in captive raccoons. Additional work is needed to determine why infection persisted among some individuals after bait consumption. Tetracycline is often incorporated into fishmeal polymer ORV baits as a biomarker. High-performance liquid chromatography analyses of bait contents 
have demonstrated that baits deliver a lower effective dose of tetracycline than intended because of degradation during the bait manufacturing process and portions of the dose being functionally unavailable by binding with polymer in the bait formulation (Johnston et al. 2005). Similar processes may have limited the effective dose of pyrantel delivered in baits and contributed to the failure to deworm three of 12 individuals. However, therapeutic use of anthelmintics often requires multiple doses to clear infection (Overgaauw 1997), and it is recommended that raccoons taken into captivity receive multiple treatments to ensure complete elimination of $B$. procyonis (Kazacos 2001). Management applications of anthelmintic baits for $B$. procyonis mitigation will require repeated bait distribution because of the potential for raccoons to be reinfected from environmental reservoirs (Hegglin and Deplazes 2008; Page et al. 2011; Smyser et al. 2013). Therefore, should initial bait contact result in reduction, but not elimination, of B. procyonis infections, raccoons likely would receive additional treatments with subsequent bait distribution.

The range of realized dosages in our study illustrates one of the challenges of using medicinal baits to manage disease among free-ranging wildlife. Our intent in anthelmintic bait development was to deliver a minimum pyrantel dose of $20 \mathrm{mg} / \mathrm{kg}$. A failure of some individuals to consume an entire bait, thereby receiving a dose below recommended therapeutic levels, may have contributed to the persistence of infection in some individuals. Furthermore, pyrantel is intended to be consumed as a single dose. However, some raccoons consumed one bait over multiple days (S.R.J. unpubl. data); it is possible that these individuals did not consume a sufficient amount of bait at one time to obtain a therapeutic dose. Images collected during our in situ trials provided no evidence of similar behavior among free-ranging raccoons; among the 22 anthelmintic and standard baits consumed by raccoons, we did not observe raccoons discarding a partially eaten bait. While this behavior may occur in the wild, the reluctance to consume baits and the consumption of only portions of baits observed in captive trials were likely exacerbated by the stress associated with transfer from the wild to the captive facility immediately before the initiation of bait trials.

We could not determine whether the failure to clear B. procyonis infection from some raccoons may have been attributable to the presence of nematodes with genotypes resistant to pyrantel. Given that freeranging raccoons would not have been treated previously with pyrantel, we would not expect anthelmintic-resistant B. procyonis to have a selective advantage over susceptible nematodes in the general population. Thus, this hypothesis for the cause of persistent infections seems unlikely. However, anthelmintic resistance among gastrointestinal helminths of domestic animals is a major challenge in veterinary medicine (Kaplan 2004; Wolstenholme et al. 2004), and similar challenges could arise with the broad-scale distribution of anthelmintic baits for B. procyonis control. Among domestic animals, emergence of anthelmintic resistance appears to be associated with a lack of refugia for anthelmintic-susceptible parasites and administration of dosages below therapeutic levels (Falzon et al. 2014). Anthelmintic bait distribution for B. procyonis control would maintain abundant refugia for susceptible nematodes. Even if broadly adopted, we would expect baiting to be restricted to urban and suburban landscapes, where the risk of human exposure is greatest. Therefore, B. procyonis infecting raccoons in outlying rural habitats would represent a large refugium with the potential to continually introduce susceptible parasites via raccoon immigration. Moreover, egg and larval stages in the environment or paratenic hosts are unaffected by raccoon 
treatment and serve as refugia. Finally, baits were developed to deliver a therapeutic dose for raccoons in the 95th percentile by weight. In management applications, the density of distributed baits would exceed raccoon densities, thus creating potential for raccoons to consume multiple baits, and would reduce the risk of under-dosing large raccoons. Collectively, multiple factors should hinder the emergence of anthelmintic resistance in B. procyonis.

Despite consumption of anthelmintic and standard baits in situ at similar rates, we observed a consistent preference by raccoons for standard baits. A greater proportion of standard baits was consumed by raccoons $(50 \%$ standard vs. $37 \%$ anthelmintic) and, when encountered in the landscape, raccoons consumed standard baits more frequently than anthelmintic baits (26\% [10/39] anthelmintic vs. 57\% [12/21] standard). In contrast, opossums seldom failed to consume a bait of either type once encountered (81\% [29/36]). Of the seven encounters in which opossums failed to consume a bait, imagery suggested opossums attempted and failed to remove the bait from the tether on three occasions rather than simply ignoring the baits. In sum, nontarget opossums were less discriminating between bait types than sympatric raccoons. Bait consumption by opossums can limit bait availability for raccoons (Olson and Werner 1999; Olson et al. 2000; Smyser et al. 2010, 2013). Therefore, if raccoons are more reluctant to consume anthelmintic baits, then opossums, as less selective foragers, could have an even greater effect on reducing bait availability for raccoons relative to standard baits. Additional work is needed to evaluate whether pyrantel pamoate in anthelmintic baits can be masked by increasing fish oil content or introducing molasses or other flavor enhancers to improve palatability (Hanlon et al. 1989).

Initial trials of a mass-producible anthelmintic bait for the control of
B. procyonis in free-ranging raccoons appear promising. The small batch of anthelmintic baits used in this trial cost $\$ 0.50 /$ bait, a savings of $\$ 0.10 /$ bait over the multiple-ingredient baits (fishmeal attractant, anthelmintic, marshmallow cream, paraffin wax) used previously in field trials (Page et al. 2011; Smyser et al. 2013). At mass production scales, the introduction of pyrantel pamoate to fishmeal polymer baits could add as little as $\$ 0.05$ to the cost of standard baits. Furthermore, by integrating pyrantel pamoate into the fishmeal matrix, the chamber of the bait remains available to deliver vaccine, medicinal, or contraceptive products. Anthelmintic baits could be coupled with an oral rabies vaccine to manage two zoonotic diseases with one bait if the addition of pyrantel does not reduce vaccine efficacy or bait palatability (Roberts and Aubert 1995). Continued work is needed to develop appropriate strategies to mitigate the risk posed by B. procyonis to human health. With refinement in dose and palatability, we believe anthelmintic baits could contribute to this goal.

\section{ACKNOWLEDGMENTS}

We thank T. Rigg for help with data collection on captive raccoons, M. Freiburger and L. Estrada for assistance with remote camera deployment and imagery assessment, and M. Smith for assistance with bait development. This research was funded by Purdue University, Indiana Department of Natural Resources (SWG T7R12 and T7R10), USDA National Rabies Management Program, and the Wheaton College Faculty Achievement Award.

\section{LITERATURE CITED}

Bauer C. 2013. Baylisascariosis-Infections of animals and humans with 'unusual' roundworms. Vet Parasitol 193:404-412.

Bauer C, Gey A. 1995. Efficacy of 6 anthelmintics against luminal stages of Baylisascaris procyonis in naturally infected raccoons (Procyon lotor). Vet Parasitol 60:155-159.

Blizzard EL, Yabsley MJ, Beck MF, Harsch S. 2010. Geographic expansion of Baylisascaris procyonis roundworms, Florida, USA. Emerg Infect Dis 16:1803-1804. 
Chavez DJ, LeVan IK, Miller MW, Ballweber LR. 2012. Baylisascaris procyonis in raccoons (Procyon lotor) from eastern Colorado, an area of undefined prevalence. Vet Parasitol 185:330334.

Falzon LC, O’Neill TJ, Menzies PI, Peregrine AS, Jones-Bitton A, vanLeeuwen J, Mederos A. 2014. A systematic review and meta-analysis of factors associated with anthelmintic resistance in sheep. Prev Vet Med 117:388-402.

Foreyt WJ. 1986. Recovery of nematode eggs and larvae in deer: Evaluation of fecal preservation methods. I Am Vet Med Assoc 189:1065-1067.

Foreyt WJ. 2001. Diagnostic parasitology. In: Veterinary parasitology reference manual, 5th $\mathrm{Ed}$. Iowa State University Press, Ames, Iowa, pp. 3-10.

Fowler ME. 2009. Restraint and handling of wild and domestic animals. 3rd Ed. Wiley, New York, New York, 488 pp.

Freuling CM, Hampson K, Selhorst T, Schröder R, Meslin FX, Mettenleiter TC, Müller T. 2013. The elimination of fox rabies from Europe: Determinants of success and lessons for the future. Philos Trans $R$ Soc Lond B Biol Sci 368:20120142.

Gavin PJ, Kazacos KR, Shulman ST. 2005. Baylisascariasis. Clin Microbiol Rev 18:703-718.

Hadidian J, Prange S, Rosatte R, Riley SPD, Gehrt SD. 2010. Raccoons (Procyon lotor). In: Urban carnivores: Ecology, conflict, and conservation, Gehrt SD, Riley SPD, Cypher BL, editors. John Hopkins University Press, Baltimore, Maryland, pp. 35-47.

Haider S, Khairnar K, Martin DS, Yang J, Ralevski F, Kazacos KR, Pillai DR. 2012. Possible petassociated baylisascariasis in child, Canada. Emerg Infect Dis 18:347-349.

Hanlon CA, Hayes DE, Hamir AN, Snyder DE, Jenkins S, Hable CP, Rupprecht CE. 1989. Proposed field evaluation of a rabies recombinant vaccine for raccoons (Procyon lotor): Site selection, target species characteristics, and placebo baiting trials. J Wildl Dis 25:555-567.

Hegglin D, Deplazes P. 2008. Control strategy for Echinococcus multilocularis. Emerg Infect Dis 14:1626-1628.

Hegglin D, Deplazes P. 2013. Control of Echinococcus multilocularis: Strategies, feasibility, and cost-benefit analysis. Int J Parasitol 43:327-337.

Hegglin D, Ward PI, Deplazes P. 2003. Anthelmintic baiting of foxes against urban contamination with Echinococcus multilocularis. Emerg Infect Dis 9:1266-1272.

Hernandez SM, Galbreath B, Riddle DF, Moore AP, Palamar MB, Levy MG, DePerno CS, Correa MT, Yabsley MJ. 2013. Baylisascaris procyonis in raccoons (Procyon lotor) from North Carolina and current status of the parasite in the USA. Parasitol Res 112:693-698.
Huff DS, Neafie RC, Binder MJ, DeLeõn GA, Brown LW, Kazacos KR. 1984. The first fatal Baylisascaris infection in humans: An infant with eosinophilic meningoencephalitis. Pediatr Pathol 2:345-352.

Johnston JJ, Primus TM, Buettgenbach T, Furcolow CA, Goodall MJ, Slate D, Chipman RB, Snow JL, DeLiberto TJ. 2005. Evaluation and significance of tetracycline stability in rabies vaccine baits. J Wildl Dis 41:549-558.

Kaplan RM. 2004. Drug resistance in nematodes of veterinary importance: A status report. Trends Parasitol 20:477-481.

Kazacos KR. 1986. Raccoon ascarids as a cause of larva migrans. Parasitol Today 2:253-255.

Kazacos KR. 2001. Baylisascaris procyonis and related species. In: Parasitic diseases of wild mammals, Samuel WM, Pybus MJ, Kocan AA, editors. Iowa State University Press, Ames, Iowa, pp. 301-341.

LoGiudice K. 1995. Control of Baylisascaris procyonis (Nematoda) in raccoons (Procyon lotor) through the use of anthelmintic baits: A potential method for reducing mortality in the Allegheny woodrat (Neotoma floridana magister). MS Thesis, Rutgers University, New Brunswick, New Jersey, 78 pp.

MacInnes CD, Smith SM, Tinline RR, Ayers NR, Bachmann P, Ball DGA, Calder LA, Crosgrey SJ, Fielding C, Hauschildt P, et al. 2001. Elimination of rabies from red foxes in eastern Ontario. J Wildl Dis 37:119-132.

Olson CA, Mitchell KD, Werner PA. 2000. Bait ingestion by free-ranging raccoons and nontarget species in an oral rabies vaccine field trial in Florida. J Wildl Dis 36:734-743.

Olson CA, Werner PA. 1999. Oral rabies vaccine contact by raccoons and nontarget species in a field trial in Florida. J Wildl Dis 35:687-695.

Overgaauw PAM. 1997. Aspects of Toxocara epidemiology: Toxocarosis in dogs and cats. Crit Rev Microbiol 23:233-251.

Page LK. 2013. Parasites and the conservation of small populations: The case of Baylisascaris procyonis. Int $J$ Parasitol Parasites Wildl 2:203-210.

Page LK, Beasley JC, Olson ZH, Smyser TJ, Downey M, Kellner KF, McCord SE, Egan TS II, Rhodes OE Jr. 2011. Reducing Baylisascaris procyonis roundworm larvae in raccoon latrines. Emerg Infect Dis 17:90-93.

Page LK, Swihart RK, Kazacos KR. 1998. Raccoon latrine structure and its potential role in transmission of Baylisascaris procyonis to vertebrates. Am Midl Nat 140:180-185.

Page LK, Swihart RK, Kazacos KR. 1999. Implications of raccoon latrines in the epizootiology of baylisascariasis. J Wildl Dis 35:474-480.

Page LK, Swihart RK, Kazacos KR. 2001. Changes in transmission of Baylisascaris procyonis to 
intermediate hosts as a function of spatial scale. Oikos 93:213-220.

Pipas MJ, Page LK, Kazacos KR. 2014. Surveillance for Baylisascaris procyonis in raccoons (Procyon lotor) from Wyoming, USA. I Wildl Dis 50: 777-783.

R Development Core Team. 2014. R: A language and environment for statistical computing. R Foundation for Statistical Computing, Vienna, Austria. http://www.R-project.org/. Accessed February 2015 .

Roberts MG, Aubert MFA. 1995. A model for the control of Echinococcus multilocularis in France. Vet Parasitol 56:67-47.

Sidwa TJ, Wilson PJ, Moore GM, Oertli EH, Hicks BN, Rohde RE, Johnston DH. 2005. Evaluation of oral rabies vaccination programs for control of rabies epizootics in coyotes and gray foxes: 1995-2003. J Am Vet Med Assoc 227:785792.

Slate D, Algeo TP, Nelson KM, Chipman RB, Donovan D, Blanton JD, Niezgoda M, Rupprecht CE. 2009. Oral rabies vaccination in North America: Opportunities, complexities, and challenges. PLoS Negl Trop Dis 3:e549.

Smyser TJ, Beasley JC, Olson ZH, Rhodes OE Jr. 2010. Use of rhodamine B to reveal patterns of interspecific competition and bait acceptance in raccoons. J Wildl Manage 74:1405-1416.
Smyser TJ, Page LK, Johnson SA, Hudson CM, Kellner KF, Swihart RK, Rhodes OE. Jr. 2013. Management of raccoon roundworm in freeranging raccoon populations via anthelmintic baiting. J Wildl Manage 77:1372-1379.

Sorvillo F, Ash LR, Berlin OGW, Yatabe J, Degiorgio C, Morse SA. 2002. Baylisascaris procyonis: An emerging helminthic zoonosis. Emerg Infect Dis 8:355-359.

Sprent JFA. 1992. Parasites lost. Int J Parastiol 22:139-151.

Tsukada H, Hamazaki K, Ganzorig S, Iwaki T, Konno K, Lagapa JT, Matsuo K, Ono A, Shimizu M, Sakai H, et al. 2002. Potential remedy against Echinococcus multilocularis in wild red foxes using baits with anthelmintic distributed around fox breeding dens in Hokkaido, Japan. Parasitology 125:119-129.

Van Wyk JA, Van Wyk L. 2002. Freezing of sheep faeces invalidates Haemonchus contortus faecal egg counts by the McMaster technique. Onderstepoort J Vet Res 69:299-304.

Wolstenholme AJ, Fairweather I, Prichard R, von Samson-Himmelstjerna G, Sangster NC. 2004. Drug resistance in veterinary helminths. Trends Parasitol 20:469-476.

Submitted for publication 23 September 2014. Accepted 10 January 2015. 